\title{
Sanín Cano, Amigo e Intérprete de la Argentina
}

I

I A última visita que Sanín Cano hizo a la Argentina data, si no nos equivocamos, de doce años atrás. Un lustro antes de que viniera como delegado de Colombia al XIV Congreso Internacional de los P. E. N. Clubs, pasó entre nosotros una de sus temporadas habituales. En aquella oportunidad varios redactores de La Vida Literaria disfrutamos el privilegio de compartir su mesa en un almuerzo sencillo y cordial de auténtica camaradería. No se efectuó el agasajo en ningún restaurant copetudo del centro, sino en un merendero típico situado frente a los jardines de la Recoleta. Durante la colonia los padres Recoletos levantaron en ese sitio de Buenos Aires un convento, del cual queda ahora la iglesia del Pilar y junto a ella, la postrer morada de patriciado porteño y de la clase que se desvive por el sueño del nicho propio. No pueden pues concurrir al mesón cuyano comensales de ánimo mortecino ni impresionables por las sugestiones de la funeraria vecindad. Tampoco se presta el lugar para ofrecer demostraciones de protocolo a huéspedes ceremoniosos. Otra cosa muy distinta ocurre con don Baldomero que irradia una hidalga llaneza y un "esprit" de comunicativas calorías. Bien es cierto que la especialidad de la acreditada casa consiste en las famosas empanadas mendocinas que el dueño parecería recomendar con la convicción de un axioma: "iDése usted un gusto en vida y pruébelas antes de entrar en su respectivo mausoleo!" Luego para que la intimidad del encuentro fuera perfecta, nos sacamos una de esas fotos domingueras, orgullo de los álbumes familiares. Allí apare- 
cen rodeando al maestro Francisco Romero, Samuel Glusberg, Justo P. Sáenz, César Tiempo, el que esto evoca y otros redactores del periódico que naturalmente reprodujo la primicia gráfica.

Tanto el ambiente acogedor del rincón provinciano como el tradicional barrio porteño que le sirve de marco, predisponían a estar a gusto entre amigos de todas las horas. No nos habíamos dado cita para rendir un homenaje estirado al "ilustre visitante" de que hablan las crónicas, sino para estar cerca del viejo, admirado y querido compañero. Sólo se festeja así, franca y afectıosamente, a los invitados de confianza. $Y$ ese era entonces y sigue siendo para nosotros don Baldomero, pujante patriarca de las letras hispanoamericanas cuya amistad con la Argentina hace rato que cumplió las bodas de plata.

Como Bello, Sarmiento, Martí y Darío, Sanín Cano encarna y prolonga el signo de los grandes adalides del Nuevo Mundo ya que a todos se les disputan otras patrias además de la nativa. Tal es la prerrogativa de los promotores del espíritu americano: crear amistades vivas, suscitar fuentes de mutuo conocimiento y de inteligencia entrañable entre aquellos que se afanan por descifrar el alma de estos pueblos y por expresar sus impulsos más puros. De ahí que hablemos de Sanín Cano como de uno de los nuestros. Así queremos recordarlo hoy quince años después de aquella tarde, rindiendo culto a la cocina criolla y congregados a unos pasos de los gomeros que plantó el autor de Facundo. La imagen nos hace revivir el gozo de su compañía fraterna, de su charla sabrosa y de las iluminaciones de su sonrisa, llenas de inteligencia y de calor humano.

Fuera de sus largas residencias en Londres y Madrid, Buenos Aires ha sido uno de los dilectos fondeaderos espirituales de este peregrino de Colombia, como se ha llamado a sí mismo. De tal modo ha podido interiorizarse de las manifestaciones de nuestra vida pública y privada, mezclándose a la experiencia de cada día. Ese conocimiento le ha dado materia a Sanín Cano para interpretar los hombres y las cosas del país en su copiosa producción periodística, una gran parte de ella difundida desde las columnas de La Nación, diario del que es un colaborador veterano. Estadistas, políticos, científicos; artistas, escritores, hombres y mujeres de mundo, infinidad 
de figuras representativas de la Argentina le inspiraron a Sanín Cano reflexiones sagaces y personales, cada una de ellas examinada dentro del círculo social o cultural donde gravita. La personalidad de Lugones, el advenimiento de Alfonsina Storni o los rasgos de nuestros humoristas, fueron captados por él magistralmente. Tenemos presente, entre otras, la serie de admirables medallones que tituló "Kodak argentino" (1927), en los cuales pone de relieve su extraordinario poder de observación, su maestría de psicólogo, su lapidaria facultad de síntesis, en suma, su arte de la semblanza breve. Esa galería nos hace pensar que si Teofrasto empezó a escribir los célebres Caracteres a los noventa y nueve años, el maestro Sanín por la lozanía de su espíritu, está en condiciones de repetir la proeza. Con la ventaja de que sólo tendría que completar esa serie de perfiles americanos.

Ahora bien, estamos seguros de que este enfoque argentino de la múltiple personalidad de Sanín Cano encontrará ecos similares y correlativos en México, Cuba, Chile o cualquiera otra de las naciones hermanas. De todas ellas posee una minuciosa información y un cabal concepto, pues como él afirmó del insigne peruano Mariátegui, "pertenece ya a la categoría de los escritores universales de América". Sanín cumple de este lado del Atlántico una misión parecida a la de Salvador de Madariaga en Europa: ambos calan en la diversidad de las idiosincrasias nacionales, con el anhelo de esclarecer e indagar bases sobre que tender los arcos de la unidad continental. Uno y otro, expertos en letras y autores ingleses, dignifican el periodismo de alto bordo propagando dichos ideales, bajo la común simpatía por los ensayos de psicología comparada de pueblos. Alguna vez nuestro celso vigía, instalado en Londres, le salió al paso a Gustavo Le Bon y a otros autores de vulgarizaciones sociológicas, bastante vulgares, en las que se desfigura y ridiculiza a Latinoamérica. Replicando a uno de esos detractores profesionales to hizo blanco de su vena humorística con sordina. "Benjamín Kiddl fué uno de esos autores que tienen poco que decir —apostilla Sanín-, escriben un libro y convencidos de la verdad de sus aserciones, vuelven a escribirlo con diferentes títulos y en formas diversas." Aludía a The control of the tropics. 
Medio siglo lleva Sanín Cano montando guardia intelectual en la patria grande que es el continente de nuestra habla y de nuestra mentalidad criolla en la vertiente de la influencia latina y sajona. Pocos tan eruditos en las literaturas inglesa y germánica, aunque le es aplicable la salvedad que él apunta al margen de FitzmauriceKelly: "todo lo contrario de la idea popular sobre el carácter del erudito." Su profunda versación en estos dos orbes de la cultura traduce secretas preferencias temperamentales y aproximaciones filosóficas y estéticas, todo lo cual coloca a su obra en lugar aparte en medio de la generación modernista, casi toda enfeudada al meridiano de París El pensamiento y la expresión de Sanín Cano trasuntan el amor a las cosas concretas y se ajustan a la organización de las ideas que distinguen al espíritu inglés, empírico y constructivo. Confirman ese parentesco el culto a la economía del discurso dentro de una austera elegancia, su expresión directa y su mismo sentido del humor. En el plano de la formación intelectual sobresạle el inconfundible sedimento con que los estudios científicos fertilizan en la tierra de Aldous Huxley la vocación literaria. Se explica así su temprana contribución al re-descubrimiento de la obra de Guillermo Enrique Hudson, naturalista incomparablemente refundido en la intensa intuición del poeta y uno de nuestros máximos descriptores del hombre de la pampa.

Dichas modalidades subordinadas al fuerte sello individual de Sanín Cano configuran su acento de humanista moderno, de conciencia rectora de Hispanoamérica que está de vuelta de los sirenismos europeizantes de moda, por lo mismo que su concepción del Nuevo Mundo y de su destino se nutre fundamentalmente de la mejor tradición de la cultura occidental. Esa prédica de Sanín Cano está presente en su incansable mensaje en su doble función de escritor de envergadura y de periodista de ideas, por más que renuncie a divulgarlas a través del libro, lo que nadie lamenta más que sus admiradores.

Lo sorprendente es que la inquietud universal de Sanín se manifestó en plena mocedad y que llevado por tal ansia tuvo acceso a lecturas apenas difundidas por entonces en Europa en círculos de minoría. Con nostalgias de su Bogotá natal, él mismo escribía desde Londres en 1913: "Hace veinte años, en una remota capital sudamericana, las obras y las ideas de Nietzsche eran alimento de los estu- 
diosos y materia de alusiones en la prensa diaria." Remy de Gourmont comentaba la Revista Contemporánea que Sanín animaba, conocedor ya de varias literaturas en su propio idioma. Basta decir que a fines del siglo pasado, cuando Unamuno se iniciaba en lengua danesa para leer a Kierkegaard, Sanín Cano en "la remota capital sudamericana" emprendía el mismo aprendizaje para leer a Jorge Brandes, con quien luego tuvo la satisfacción de sostener una correspondencia consagratoria. De esos reconocimientos de vanguardia $y$ de sus versiones de poetas alemanes, fueron testigos entre otros amigos y discípulos, José Asunción Silva y Guillermo Valencia.

I I I

La mesura de Sanín en la apreciación de autores, libros y costumbres no se diluye en la equidistancia anodina. Su ponderación en el juicio es un dictado del criterio responsable, de un concienzudo y aquilatado discernimiento de los valores de la vida y del espíritu. Constituye la entereza en el sagaz y noble discurrir, el concierto entre el pensamiento que avanza con cautela y la probidad del que modela la opinión pública. Es la mesura del hombre noticioso y juicioso cuya apología trazó Gracián en El discreto. Equilibrio, sí, pero condicionado por un sentido operante de la medida donde se complementa la ecuanimidad en función de la agudeza crítica. No es el de Sanín un pacato eclecticismo, sino la exigencia de la mente clara que rehuye el desorden en el mismo grado que ama el diseño de las ideas, por encima del intelectualismo abstracto y unilateral. Suprema lección de aplomo fecundo unido a la más sólida versación en las disciplinas de la cultura stperior, vale decir, de la que arraiga $y$ se decanta en los insobornables estratos del ser. Porque el magisterio de Sanín Cano nace de las profundas raíces de su personalidad moral e intelectual en continuo proceso de rejuvenecimiento. Su esencial liberalismo se alimenta de la vocación de tolerancia y de simpatía. Arranca del amor al hombre y del respeto a la propia autonomía cuya garantía más consistente se apoya en el respeto al derecho del prójimo a sustentar sus puntos de vista. Es el humanismo americano, profesión de fe en la libertad que dió origen a nuestros pueblos, en el que entroncan el dominicano Pedro Henríquez Ure- 
ña, el argentino Alejandro Korn y el mexicano Alfonso Reyes, para citar sólo algunas expresiones.

$\mathrm{He}$ ahí la rica sustancia adoctrinadora que corre por el ancho cauce de los ensayos del polígrafo colombiano. Su revisión crítica de la literatura adquiere profundas perspectivas dentro del ensamblaje de su crítica de la civilización contemporánea. Tal examen no está exento de inquietud por los conflictos que engendra el desajuste entre el desarrollo técnico y la crisis de la conciencia moral, aunque se halla desprovista de tono agorero. Más que desesperar frente al temporario eclipse de la libertad y al auge neo-totalitario, lucha para encontrar los caminos que conducen a la democracia verdadera y exhorta a vencer el desaliento de los débiles. Así Sanín Cano se ha anticipado en sus penetrantes vislumbres a muchos pensadores de nombradía europea. Sólo que fiel a su natural modestia y a su desdén por toda forma de reclamo, ha preferido pasar inadvertido a los ojos del snob intelectual. En una conferencia pronunciada en Bogotá sobre "La encrucijada de la civilización" comentó su coincidencia con Spengler al estudiar las relaciones del hombre moderno con la máquina. Demás está decir que señaló la afinidad menos celoso del valor de sus atisbos que del afán de enriquecer la cultura colectiva con el debate en torno al problema. Cuando alguien le ha señalado su derecho a la prioridad, él se ha encogido de hombros y sonriente se ha dado por satisfecho con su labor de articulista. Ha reservado sus energías al planteo de un nuevo tema en lugar de preocuparse por el destino o por la repercusión de su ingente obra que anda dispersa en diarios y revistas. Durante mucho tiempo se resistió con corteses excusas al amistoso requerimiento de discípulos, compañeros y editores a fin de recoger esos trabajos en varios volúmenes. Sanín hizo, sin embargo, una excepción honrosa para nosotros los argentinos, entre los que cuenta con devotas vinculaciones. Atendiendo el ofrecimierito de su amigo Glusberg -director de Babel - autorizó la recopilación de algunos medulares ensayos y artículos en el tomo titulado La civitización manual. Justificó dicho libro editado en Buenos Aires en 1925, advirtiendo donosamente que lo hacía porque a menudo había visto reproducidos sus trabajos en la prensa y deseaba evitar nuevas erratas. Ese pudor publicitario ha sido la causa de que su producción, confinada en el periodismo, no haya alcanzado la debida resonancia que otorga el 
libro. De donde proviene el placer de raro hallazgo que ahora tiene para las nuevas generaciones, a semejanza de lo que en otro orden sucede con el eminente pensador uruguayo Vaz Ferreira.

I V

El predicamento americano del maestro Sanín no ha necesitado para cimentarse ni desplantes de foliculario ni espectaculares actitudes de polemista. Tampoco lo debe a ese tipo de campañas que en un momento dado apasionan a la opinión pública y aupan al escritor que explota el oportunismo. Nada más opuesto a su temperamento que el sensacionalismo en cualesquiera de las modalidades que dan un renombre tan accesible como fugitivo. La turbulenta vida pública de nuestros países ha creado multitud de falsos prestigios, bólidos que atraviesan el firmamento intelectual gracias a los ecos de un libelo o a la pirotecnia de unos cuantos discursos de circunstancias. Cualquier tiranuelo de turno tan pronto confiere privanzas como las suprime por puro e idéntico capricho. Manosea así dos veces al escritor palaciego de ayer, pues lo convierte en un favorito en desgracia. Este mañana, del otro lado de la frontera, se improvisa en Júpiter de la primera redacción de provincia que halla en la ruta del consabido exilio.

Sanín Cano ha sabido mantenerse lejos de esa lonja de dispensas cortesanas. Se ha mostrado indiferente a su sensualismo y, en consecuencia, ha sido ajeno a los contragolpes de las prebendas que a la larga son caedizas. $\mathrm{Ha}$ debido, pues, sonreír piadosamente con una benévola disculpa ante las invectivas en prosa y verso de muchos inconsolables literatos. Sanín, embajador permanente de las letras continentales, los ha visto perder la canonjía y con ella la llave de su difusión bien administrada en la prensa, aunque a título precario. La invariable bonhomía del maestro fué un bálsamo para los que durante cerca de medio siglo llamaron la atención vociferando contra el imperialismo, por ejemplo, y luego, encanecidos y claudicantes, sirvieron al primer gobierno que arrendó su pluma, por más que estuviera sometido a aquellos intereses tentaculares. De esos relumbrones efímeros se encuentran repletas las letras hispanoamericanas en lo que va del siglo $\mathrm{xx}$. Su impaciencia de publicidad en- 
sombreció con oceános de tinta alternativamente panfletaria y aduladora, el periodismo del Nuevo Mundo. Frente a ellos, la dignidad cívica y política de don Baldomero se recorta en sus líneas de admirable consecuencia, nunca quebrantada. La conducta ideológica, coherente y firme del ilustre octogenario, se destaca en medio de las apostasías de tantos colegas, los cuales para que el contraste sea más grave, caen víctimas de la concupiscencia en plena madurez.

$\mathrm{V}$

Sanín Cano posee vastos conocimientos lingüísticos, no obstante to cual su prosa reune cautivadoras prendas. Esto que parece una paradoja, es para nosotros el mejor elogio de su elocución aséptica, severamente esterilizada de tropos y demás tropicalismo. En su limpia frase - rasurada como el rostro- construída por un armonioso rigor de pensamiento, el filólogo se abstiene de exhibir sobre el mostrador las tecniquerías del oficio, en obsequio al buen gusto y a los dones de sensibilidad que no lo abandonan nunca. El castellano de Sanín es de raigambre castiza, virtud peculiar de las letras colombianas, si bien el suyo se muestra particularmente desembarazado de incisos y flexible a las modulaciones que el genio del idioma reclama con el trasplante a estas tierras. El libre movimiento de sus giros no es el de una lengua encerrada en un arcón y momificada por los resabios peninsulares; por el contrario, denuncia al órgano vivo de la civilización y la cultura del Nuevo Mundo que están forjándose. Podríamos aquí invocar el lema propuesto por Amado Alonso con su indiscutida autoridad: "El español, obra común de cultura." Si los americanos nos resignáramos a ser inquilinos del español y no aspiráramos a su dominio con iguales títulos, estaría amenazada su gloriosa supervivencia. Dicho sea esto como un compromiso de custodia que acaba de ser ratificado con fervor en los recientes homenajes a Cervantes.

Así lo interpreta Sanín Cano cuya propiedad, diafanidad y pulcritud idiomáticas son aptas para expresar con una concisa y elegante soltura, el sentimiento de la vida moderna. Se trata de un instrumento verbal curado por el trasiego de un amplio saber $\mathrm{y}$, singularmente, por su compenetración con diversas culturas que se precipi- 
tan en el laboratorio americano. Y ya dijimos que el espíritu de este egregio escritor del Nuevo Mundo está abierto como pocos, al tráfico de las ideas de calado universal.

Otro gran colombiano - Germán Arciniegas- observó que a Sanín se le llama maestro no porque enseña, sino principalmente porque a sus años todavía estudia sin descanso. : Qué mejor enseñanza para los jóvenes de todas las edades que su ejemplo! Sea como fuere, el apelativo de maestro viene espontáneamente a los labios cuando se pronuncia el nombre de Sanín Cano de un extremo al otro del continente. Proclaman su magisterio la excelencia del ensayista, la autoridad del filólogo, el difícil dosaje de su humorismo, el secreto de captar matices de la inteligencia americana con la imperturbable objetividad de un hispanista británico y el amor que pone quien como él analiza nuestras cosas desde adentro. Con el título de maestro lo saludan los expertos en el periodismo, función que ha elevado al nivel de la cátedra durante cincuenta años, prodigando hondos conceptos y finuras de estilo en la glosa nuestra de cada día. No menos magistral es su libro publicado hace poco, Letras colombianas, modelo de manuales de historia de la literatura que desearíamos ver ampliado, hasta darle contornos continentales. En fin, son los incontables discípulos de Sanín Cano los que decretaron cordialmente su rango de maestro y director de conciencia de varias generaciones americanas. Discípulos, es decir, aprendices de la alta disciplina de su espíritu generoso, tan pronto a manifestar su admiración a los creadores de belleza como su solidaridad con las conciencias libres.

Luis Emilio Soto, Buenos Aires. 
